\title{
La cartografía de las compañías mineras: el Archivo Histórico Minero de la Fundación Río Tinto
}

Juan Manuel Pérez López, director del Archivo Histórico Minero Fundación Río Tinto

A finales del siglo XIX se va a producir un proceso industrializador en Andalucia como consecuencia de la II Revolución Industrial; uno de los sectores que más contribuyeron a este desarrollo económico fue sin duda la minería. Se necesitaba cobre para la industria eléctrica y azufre para su transformación en ácido sulfúrico, dos minerales que se encontraban en la pirita onubense. Una vez agotado el zolfo italiano y con la crisis de la minería británica, que habian sido los que tradicionalmente colmaban las necesidades del mercado, coincidiendo con algunas innovaciones tecnológicas y una legislación española más permisiva (Ley de Minas de 1868), se generó una auténtica fiebre minera en la denominada Faja Pirítica Ibérica. Aunque, paradójicamente, la mayor parte de esta inversión sería efectuada por extranjeros, como en el caso de las minas de Río Tinto, que eran las más ricas e importantes de la Corona, y hasta entonces tan sólo habian sido cedidas en formas de asiento, arrendadas o explotadas directamente por la Real Hacienda a través del Estado. Pero, debido a la crisis financiera del Estado español y la descapitalización de la economía, se inició un proceso para la venta de las minas de Río Tinto que culminará con la Ley de 17 de febrero de 1873 de la Asamblea Nacional, adjudicándolas a la casa Matheson y compañía, que posteriormente constituirá la Rio Tinto Company Limited (RTCL).

El fondo Minas de Río Tinto, generado por la citada Rio Tinto Company Limited hasta 1954, cuando se produce la nacionalización de las minas, y desde entonces por compañias españolas (como Compañía Española de Minas de Riotinto, Río Tinto Patiño, Explosivos Río Tinto, Río Tinto Minera, etc.), constituye el grueso de la documentación del Archivo Histórico Minero de Fundación Río Tinto. Además están depositados otros fondos como el del Instituto Seamens, Sánchez Mora, Minas de Peña del Hierro, Sociedad Minera de Nerva, Mina de Concepción y Sociedad Francesa de Piritas de Huelva, que prácticamente hasta su creación no habian tenido ninguna respuesta para su conservación y organización, ni ningún tratamiento archivistico adecuado por parte de ninguna institución pública o privada especializada. En la actualidad hay unas 33.000 unidades de instalación documentales dispuestas a la investigación, aunque hay que advertir que los trabajos de organización siguen ejecutándose en la actualidad por lo que las unidades de consulta se seguirán incrementando.

La documentación organizada está distribuida en cuatro departamentos: Archivo, Cartoteca, Fototeca y Biblioteca. En cuanto a la producción documental cartográfica para la explotación de las minas, el plano más antiguo que conservamos en nuestra Cartoteca, como documentación asociada, fue realizado en 1828 por Joaquín Ezquerra del Bayo', y señala con bastante precisión los accidentes geográficos como el nacimiento del río Tinto, cerro Colorado, Salomón, San Dionisio, etc., así como las instalaciones mineras y trabajos procedentes de los periodos de explotación de los asientos reales (socavones, pozos, cañerías, escoriales, restos de vías romanas, etc.). Quizás fue levantado con motivo de la cesión que se iba a producir a favor del marqués de Remisa en 1829 por un periodo de 20 años, a pesar de la oposición de Fausto de Elhuyar, como Director General de Minería, que previamente había informado de la necesidad de su rehabilitación².

La poca rentabilidad y la alternancia en los periodos de explotación determinaron nuevos replanteos de las concesiones mineras y la verificación de operaciones de deslindes que, unido a la necesidad de control de la actividad por parte del Estado, hicieron necesario la producción de planos, como el levantado en 1838 de nuevo por Joaquin Ezquerra del Bayo ${ }^{3}$ como inspector general del Cuerpo de Ingenieros de Minas para el control de las actividades del marqués de Remisa y que en su día también fue depositada copia en nuestros fondos. Pero sobre todo se levantarán numerosos planos cuando se inicie el proceso de venta de las minas a través de los ingenieros comisionados para su valoración, Anciola y Cossío en 1856, Gómez de Salazar en 1867, Rúa Figueroa en 1868, o la misma Comisión de Ventas de las minas en 1871, encabezada por su presidente Luis de la Escosura, que establecen los primeros trabajos cartográficos antes de la llegada de los ingleses, con un alto grado de precisión en la localización y el número de las masas de los yacimientos minerales. Muchos de estos planos fueron publicados también en la Revista Minera del Instituto Geológico y Minero de España.

Desde entonces la producción de documentos cartográficos se incrementó notablemente, pero sin duda, con la llegada de la RTCL en 1873 , se va a convertir en una producción continua y estable como consecuencia de la creación de los departamentos técnicos para la exploración y explotación del mineral, como Geología, Topografía, Sala de dibujo, etc. Además, la RTCL contrató como asesores desde muy temprano a ingenieros españoles, como Gonzalo y Tarin (1898-1905)4, que se encargaron de los planes de labores 
con sus pertinentes levantamientos de planos para la inspección en Jefatura de Minas (C-0469, C-01161, C-02009, C-02010, C-02015, C-2016 AFRT).

Actualmente el Archivo de Minas de Río Tinto custodia una extraordinaria documentación de carácter gráfico compuesta por unos 60.000 documentos aproximadamente, incluyendo mapas, planos y dibujos técnicos. Esta documentación se ha clasificado en cinco grandes grupos:

A. Cartografía general, que comprende planos y mapas provinciales, municipales, comarcales, propiedades de las compañias mineras, etc., que hacen un total de 2.863 documentos.

C. Cartografía específicamente minera que localizan la situación de las distintas explotaciones, terrenos donde se ubican las instalaciones, etc., con 2.005 documentos.

D. Maquinaria que incluye piezas de maquinaria de todo tipo utilizadas en las distintas dependencias mineras, pero predomina sobre todo las piezas utilizadas para la construcción y reparación del ferrocarril. Compuesta por 45.000 documentos aproximadamente.

E. Grupo de Arquitectura, que abarca planos de edificios, casas, construcciones, etc., con un total de 6.500 documentos aproximadamente.

F. Perfiles, secciones, pisos y niveles de las minas, compuesta por 8.500 documentos aproximadamente.

Las fases que estamos siguiendo para su ordenación son: clasificación y ordenación, inventario, catalogación y microfilmación. Y la documentación dispuesta a la investigación es la referida en la tabla.

Para la organización de la documentación cartográfica, la perteneciente a los grupos A y C, que suman un total de 4.000 mapas aproximadamente, contamos con la colaboración del Instituto de Cartografía de Andalucia de la Consejería de Obras Públicas y Transportes gracias al convenio firmado para la constitución de un fondo documental cartográfico, que forma parte de la Cartoteca Histórica de Andalucía. La documentación ha sido catalogada en formato Marc, mediante fichas catalográficas que recogen muchos datos pertenecientes a dichos planos y mapas. Se ha efectuado una copia para seguridad y consulta en tarjetas de aperturas de $35 \mathrm{~mm}$. La cronologia de dicha documentación comprende desde el siglo XIX hasta la década de 1980, a pesar de que el criterio de selección establecía los años 60 como límite para su inclusión. Las escalas también son variadas, siendo las más frecuentes las que oscilan entre 1:500 y 1:10.000. Los soportes sobre los que se ha realizado la documentación son fundamentalmente papel, papel vegetal y tela encerada $y_{\text {, en }}$ escasas ocasiones, poliéster.

Para la consulta, además del catálogo editado por el Instituto de Cartografía Andaluza ${ }^{5}$, tanto de los campos de descripción como para visualizar los planos digitalizados, hemos instalado el pro-

\begin{tabular}{|c|c|c|c|}
\hline \multicolumn{4}{|c|}{ DOCUMENTACIÓN GRÁFICA } \\
\hline \multirow[t]{2}{*}{ Grupo A } & MRT & 2.800 & $\begin{array}{l}\text { Inventariado, catalogado y } \\
\text { digitalizado }\end{array}$ \\
\hline & MC & 63 & Inventariado, catalogado \\
\hline \multirow[t]{3}{*}{ Grupo C } & MRT & 1.222 & $\begin{array}{l}\text { Inventariado, } \\
\text { catalogado y digitalizado }\end{array}$ \\
\hline & SFPH & 572 & \multirow{2}{*}{$\begin{array}{l}\text { Inventariado y } \\
\text { catalogado }\end{array}$} \\
\hline & MC & 211 & \\
\hline \multirow[b]{2}{*}{ Grupo D } & MRT & 1.899 & \multirow[b]{2}{*}{ Inventariado } \\
\hline & $M C$ & 355 & \\
\hline \multirow[b]{2}{*}{ Grupo E } & MRT & 378 & \multirow[b]{2}{*}{ Inventariado } \\
\hline & $M C$ & 33 & \\
\hline \multirow{2}{*}{ Grupo F } & MRT & 654 & Inventariado \\
\hline & MC & 177 & Inventariado y catalogado \\
\hline Total & & 8.364 & \\
\hline
\end{tabular}

grama WINISIS con la base de dato ccrecu, cuya estructura es compatible con la que tenemos catalogada la Cartoteca, CDS/ISIS.

El acceso a estos documentos cartográficos es fundamental para la reconstrucción del pasado histórico y del proceso productivo minero. A través de ellos obtenemos información sobre el territorio y la transformación antrópica de éste, que se hace fundamental para el estudio, además de la Minería, de algunas ciencias como la Biología, Geografía, Urbanismo, etc.

Pero además del valor instrumental de la transmisión de la información, en muchos casos tienen un valor patrimonial como testimonio material de la industrialización, además de su valor estético, por lo que se hace imprescindible su conservación y difusión como parte fundamental del patrimonio histórico andaluz.

\section{Notas}

1 Plano de la población y territorio de las Reales Minas de Rio-Tinto trazado y dibujado por Joaquín Ezquerra. Año 1828. Escala 1:10.000. 1928. Real Academia de la Historia. C/ld. ICA. 88-016295. Y Archivo Histórico Minero Fundación Río Tinto. A00818. (Dig. 10997100).

2 "Relación de las minas de cobre de Río-Tinto" Manuscrito de Fausto Elhuyar. Biblioteca del Instituto Geológico y Minero. 12 de febrero de 1823. Madrid.

${ }^{3}$ Término de las Minas de Rio-Tinto. Lámina II. Joaquín Ezquerra. Escala 1:1.250. 1838. Servicio Geográfico del Ejército. Arm. TBLA. 7a Carp. 4a núm. 536. ICA. 880000616.

${ }^{4}$ Staff book no 2. pp. 124. AFRT.

${ }^{5}$ Catálogo de cartografía histórica de Huelva. ICA. Junta de Andalucía. Consejería de Obras Públicas y Transportes. Sevilla, 1995. 